\title{
Quantifying Species Populations in Multivalent Borohydride Electrolytes
}

\author{
Nathan T. Hahn, ${ }^{\mathrm{a}, \mathrm{b}, *}$ Julian Self, ${ }^{\mathrm{a}, \mathrm{c}, \mathrm{d}}$ Kee Sung Han, ${ }^{\mathrm{a}, \mathrm{e}}$ Vijayakumar Murugesan, ${ }^{\mathrm{a}, \mathrm{e}}$ Karl T. \\ Mueller, ${ }^{\mathrm{a}, \mathrm{e}}$ Kristin A. Persson, ${ }^{\mathrm{a}, \mathrm{c}, \mathrm{f}}$ Kevin R. Zavadil ${ }^{\mathrm{a}, \mathrm{b}}$
}

aJoint Center for Energy Storage Research, Lemont, IL, 60439

${ }^{b}$ Material, Physical and Chemical Sciences Center, Sandia National Laboratories, Albuquerque, NM 87185

${ }^{c}$ Department of Materials Science and Engineering, University of California, Berkeley, CA 94720

${ }^{\mathrm{d}}$ Energy Technologies Area, Lawrence Berkeley National Laboratory, Berkeley, CA 94720

ePhysical and Computational Sciences Directorate, Pacific Northwest National Laboratory, Richland, WA 99354

${ }^{\mathrm{f}}$ The Molecular Foundry, Lawrence Berkeley National Laboratory, Berkeley, CA 94720

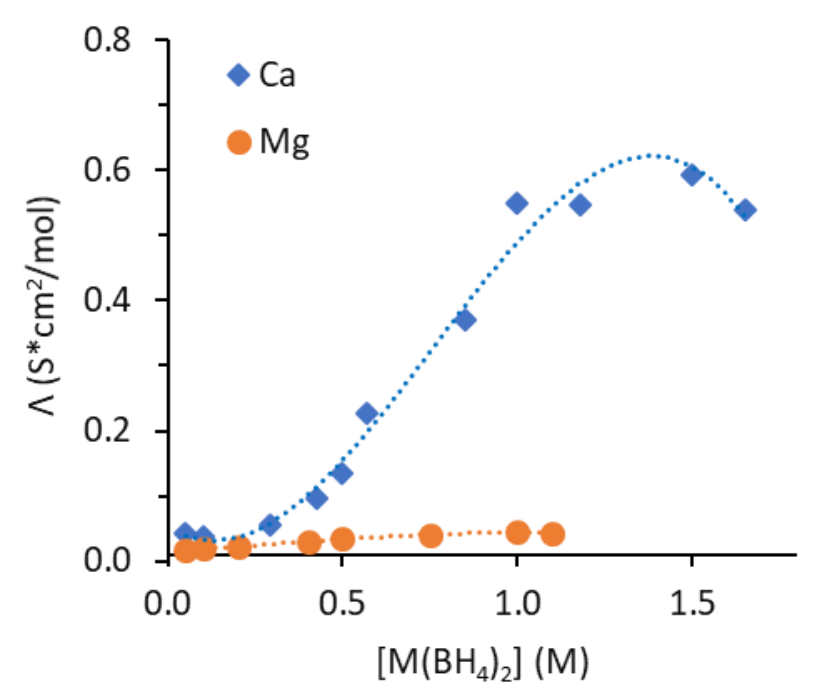

Figure S1. Molar conductivity plotted as a function of salt concentration for $\mathrm{Mg}\left(\mathrm{BH}_{4}\right)_{2}$ and $\mathrm{Ca}\left(\mathrm{BH}_{4}\right)_{2}$ electrolytes in THF, adapted from Ref. 1 with permission from the Royal Society of Chemistry. ${ }^{1}$ Polynomial fits are shown to guide the eye.

\section{Dielectric Spectroscopy Methods}

As mentioned in the main text, dielectric spectra ( $\varepsilon^{\prime}$ and $\varepsilon$ "') were measured between 0.5 and 26.5 GHz. The $\varepsilon$ " values were corrected for ionic conductivity. Extraction of the overall dielectric constant (static permittivity, $\varepsilon_{\mathrm{r}}$ ) was accomplished by fitting both the $\varepsilon^{\prime}$ and $\varepsilon$ " spectra simultaneously by discrete dipole relaxations (Debye and/or Cole-Cole) and extrapolation of the total $\varepsilon$ ' spectrum to zero frequency. This fitting was performed with very few external constraints and is intended to yield an accurate measurement of $\varepsilon_{\mathrm{r}}$ rather than provide a complete deconvolution of the individual dipolar species as is sometimes attempted. ${ }^{2}$ Many of the most polar species in $\mathrm{Ca}\left(\mathrm{BH}_{4}\right)_{2} / \mathrm{THF}$ have similar calculated relaxation 
frequencies and thus the overall $\varepsilon_{\mathrm{r}}$ is a more reliable metric. Examples of the fitted $\varepsilon$ " spectra are shown in Figure S2. The relevant fitting parameters for all solutions are shown in Table S1 and S2.

To estimate the individual species populations in $\mathrm{Ca}\left(\mathrm{BH}_{4}\right)_{2} / \mathrm{THF}$ using this technique, we rely on the fact that the overall change in $\varepsilon_{\mathrm{r}}$ for a given electrolyte relative to that of pure THF originates from the sum of the contributions of the various salt species present:

$\Delta \varepsilon_{\mathrm{r}}=\left(\varepsilon_{\mathrm{r}}-\Delta \varepsilon_{\infty}\right)_{c}-\left(\varepsilon_{\mathrm{r}}-\Delta \varepsilon_{\infty}\right)_{0}=\Sigma\left(c_{i} \Delta \varepsilon_{i}\right)$

where $c$ is concentration in $\mathrm{M}$ and $\Delta \varepsilon$ is the computed net dielectric increment in $\mathrm{M}^{-1} ; \varepsilon_{\infty}$ is the sum of higher frequency intramolecular and electronic permittivity contributions and is extracted from the fitting to isolate the contributions of dipole rotations. Because the concentrations of the various species are interrelated by the proposed overall equilibrium, $2 \mathrm{Ca}\left(\mathrm{BH}_{4}\right)_{2} \leftrightarrow \mathrm{Ca}_{2}\left(\mathrm{BH}_{4}\right)_{4} \leftrightarrow \mathrm{CaBH}_{4}{ }^{+}+\mathrm{Ca}\left(\mathrm{BH}_{4}\right)_{3}{ }^{-}$, these concentrations can be derived analytically as shown below, where $\mathrm{MON}=$ neutral monomer, $\mathrm{DIM}=$ neutral dimer, $\mathrm{CIP}=$ contact ion pair cation, and QA = quadruple anion.

$$
\begin{aligned}
& \Delta \varepsilon_{\mathrm{r}}=[\mathrm{MON}] \Delta \varepsilon_{\mathrm{MON}}+[\mathrm{DIM}] \Delta \varepsilon_{\mathrm{DIM}}+[\mathrm{CIP}] \Delta \varepsilon_{\mathrm{CIP}}+[\mathrm{QA}] \Delta \varepsilon_{\mathrm{QA}} \\
& {[\mathrm{MON}]+2[\mathrm{DIM}]+[\mathrm{CIP}]+[\mathrm{QA}]=c} \\
& {[\mathrm{CIP}]=[\mathrm{QA}]}
\end{aligned}
$$

Rearranging eq. S3:

$[\mathrm{DIM}]=\frac{c-2[\mathrm{CIP}]-[\mathrm{MON}]}{2}$

Combining eq. S2, eq. S4 and eq. S5:

$\Delta \varepsilon_{\mathrm{r}}-[\mathrm{CIP}]\left(\Delta \varepsilon_{\mathrm{CIP}}+\Delta \varepsilon_{\mathrm{QA}}\right)-\frac{c-2[\mathrm{CIP}]}{2} \Delta \varepsilon_{\mathrm{DIM}}=[\mathrm{MON}]\left(\Delta \varepsilon_{\mathrm{MON}}-\frac{\Delta \varepsilon_{\mathrm{DIM}}}{2}\right)$ (eq. S6)

Rearranging eq. S6:

$\frac{\Delta \varepsilon_{r}-[\mathrm{CIP}]\left(\Delta \varepsilon_{\mathrm{CIP}}+\Delta \varepsilon_{\mathrm{QA}}\right)-\frac{c-2[\mathrm{CIP}]}{2} \Delta \varepsilon_{\mathrm{DIM}}}{\Delta \varepsilon_{\mathrm{MON}}-\frac{\Delta \varepsilon_{\mathrm{DIM}}}{2}}=[\mathrm{MON}]$

From eq. S7, the values of $c_{i}$ can be solved if [CIP] is known. The effective ionicity, calculated from the conductivity and diffusivity measurements, provides a first order approximation of [CIP], enabling a best estimate of the precise populations as a function of salt concentration (main text Fig. 4). Without specifying [CIP], a range of populations could be present, as illustrated in Figure S6. 

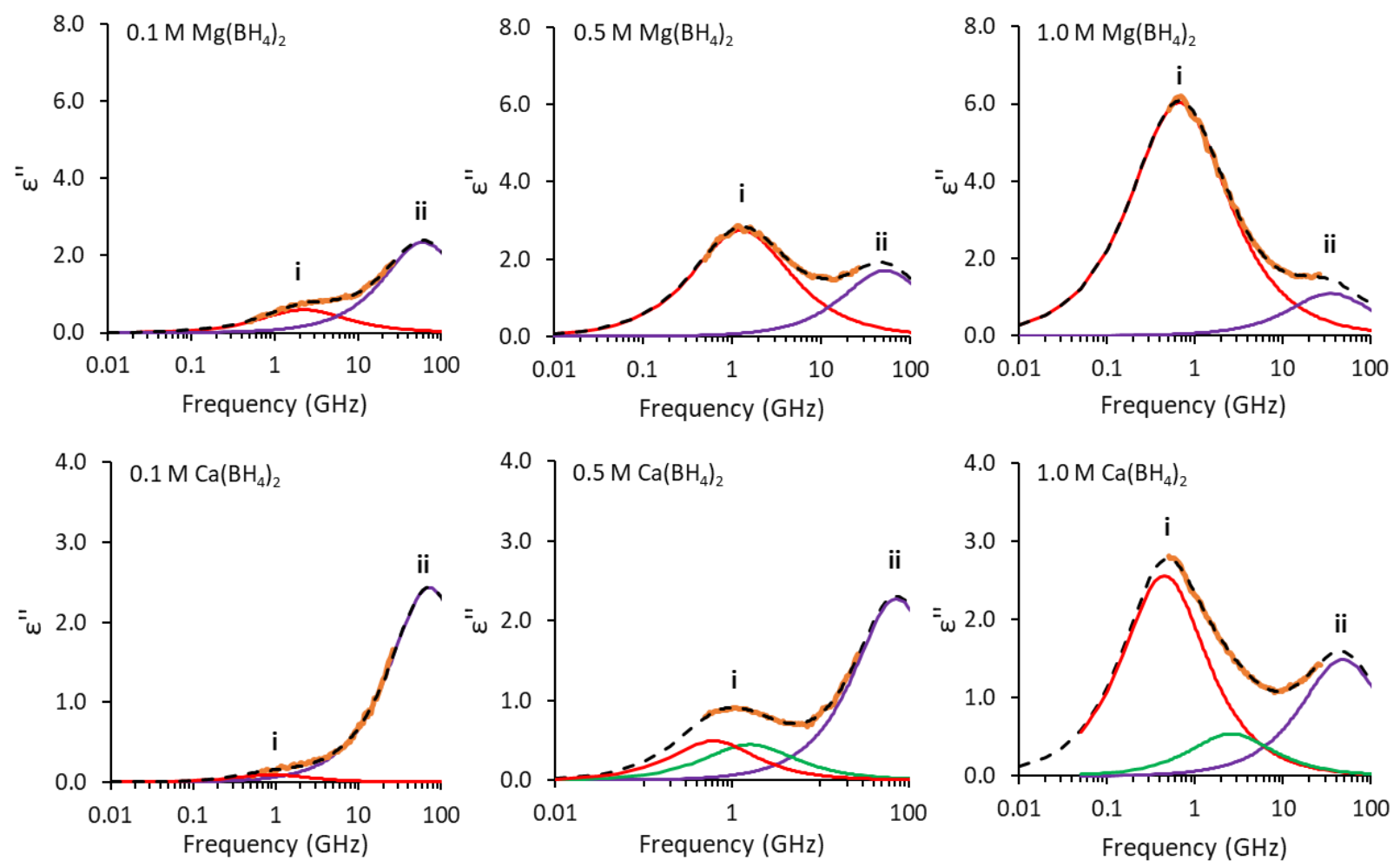

Figure S2. Example deconvoluted fits of the imaginary permittivity spectra for $\mathrm{Mg}\left(\mathrm{BH}_{4}\right)_{2} / \mathrm{THF}$ (top) and $\mathrm{Ca}\left(\mathrm{BH}_{4}\right)_{2} / \mathrm{THF}$ (bottom) at comparable salt concentrations. The deconvoluted components (solid red, green, and purple traces) correspond to associated salt species (i) or free solvent (ii). The black dashed line represents the sum of these fitted components while the solid orange line represents the data measured from 0.5 to $26.5 \mathrm{GHz}$. 
Table S1. DRS measurement parameters for $\mathrm{Mg}\left(\mathrm{BH}_{4}\right)_{2} / \mathrm{THF}$ electrolytes at $21^{\circ} \mathrm{C}$ obtained from a fit incorporating one Debye $(\alpha=0)$ and one Cole-Cole relaxation.

\begin{tabular}{|l|l|l|l|l|l|l|l|}
\hline$\left[\mathrm{Mg}\left(\mathrm{BH}_{4}\right)_{2}\right](\mathrm{M})$ & $\varepsilon_{\infty}$ & $\varepsilon_{\mathrm{THF}}$ & $f_{\mathrm{THF}}(\mathrm{GHz})^{\mathrm{a}}$ & $\varepsilon_{2}$ & $f_{2}(\mathrm{GHz})$ & $\alpha_{2}{ }^{\mathrm{b}}$ & $\varepsilon_{r}$ \\
\hline 0 & 2.59 & 4.81 & 58.8 & - & - & - & $\mathbf{7 . 4 0}$ \\
\hline 0.05 & 2.53 & 4.67 & 59.5 & 0.69 & 2.3 & 0.016 & $\mathbf{7 . 8 9}$ \\
\hline 0.1 & 2.49 & 4.69 & 60.7 & 1.29 & 2.2 & 0.052 & $\mathbf{8 . 4 7}$ \\
\hline 0.5 & 2.93 & 3.40 & 52.1 & 6.24 & 1.3 & 0.080 & $\mathbf{1 2 . 5 7}$ \\
\hline $1.0^{\mathrm{c}}$ & 3.88 & 2.17 & 33.7 & 12.13 & 0.8 & 0.075 & $\mathbf{1 8 . 1 7} \pm \mathbf{1 . 3 3}$ \\
\hline
\end{tabular}

$\mathrm{a} f=1 /(2 \pi \tau)$

${ }^{\mathrm{b}}$ Cole-Cole broadening parameter

${ }^{c}$ Values at $1.0 \mathrm{M}$ represent the average of two independent solution measurements

Table S2. DRS measurement parameters for $\mathrm{Ca}\left(\mathrm{BH}_{4}\right)_{2} / \mathrm{THF}$ electrolytes at $21^{\circ} \mathrm{C}$ obtained from a fit incorporating up to three Debye relaxations.

\begin{tabular}{|l|l|l|l|l|l|l|l|l|}
\hline$\left[\mathrm{Ca}\left(\mathrm{BH}_{4}\right)_{2}\right](\mathrm{M})$ & $\varepsilon_{\infty}$ & $\varepsilon_{\mathrm{THF}}$ & $f_{\mathrm{THF}}(\mathrm{GHz})^{\mathrm{a}}$ & $\varepsilon_{2}$ & $f_{2}(\mathrm{GHz})$ & $\varepsilon_{3}$ & $f_{3}(\mathrm{GHz})$ & \multicolumn{2}{|l|}{$\boldsymbol{\varepsilon}_{\mathbf{r}}$} \\
\hline 0 & 2.33 & 5.08 & 62.9 & - & - & - & - & $\mathbf{7 . 4 1}$ \\
\hline 0.05 & $2.33^{\mathrm{b}}$ & 4.91 & 73.7 & 0.01 & $1.0^{\mathrm{a}}$ & - & - & $\mathbf{7 . 2 5}$ \\
\hline 0.1 & & & & & & & & $\mathbf{0 . 0 2}$ \\
\hline 0.5 & $2.33^{\mathrm{b}}$ & 4.87 & 72.4 & 0.19 & 0.9 & - & - & $\mathbf{7 . 3 9}$ \\
\hline 1.0 & 2.22 & 4.55 & 73.0 & 0.96 & 1.6 & 0.99 & 0.6 & $\mathbf{8 . 7 2}$ \\
\hline 1.5 & 3.41 & 2.98 & 47.9 & 5.13 & 0.4 & 1.08 & 2.6 & $\mathbf{1 2 . 5 9}$ \\
\hline$f=1 /(2 \pi \tau)$ & 3.81 & 2.29 & 37.8 & 8.61 & 0.3 & 1.26 & 2.8 & $\mathbf{1 5 . 9 7}$ \\
\hline
\end{tabular}

$\mathrm{a} f=1 /(2 \pi \tau)$

${ }^{\mathrm{b}}$ Fixed parameter 
Table S3. Computed Magnesium Cluster Parameters from MD Simulations.

\begin{tabular}{|l|c|c|c|c|c|}
\hline \multicolumn{1}{|c|}{ Formula $^{\mathrm{a}}$} & THF Number $^{\mathrm{b}}$ & $\Delta \varepsilon_{\text {net }}{ }^{\mathrm{c}}$ & $\Delta \varepsilon_{\text {gross }}{ }^{\mathrm{d}}$ & $f(\mathrm{GHz})^{\mathrm{e}}$ & $R_{\mathrm{g}}\left(\AA^{f}\right.$ \\
\hline $\mathrm{Mg}\left(\mathrm{BH}_{4}\right)^{+}$ & 3.8 & $15.0 \pm 1.4$ & $19 \pm 1.5$ & $1.9 \pm 0.3$ & 3.2 \\
\hline $\mathrm{Mg}\left(\mathrm{BH}_{4}\right)_{2}$ & 1.9 & $8.9 \pm 1.2$ & $9.5 \pm 1.2$ & $4.5 \pm 0.8$ & 2.6 \\
\hline $\mathrm{Mg}\left(\mathrm{BH}_{4}\right)_{3}{ }^{-}$ & 0.95 & $1.5 \pm 1.1$ & $5.5 \pm 1.07$ & $4.85 \pm 0.04$ & 2.5 \\
\hline $\mathrm{Mg}_{2}\left(\mathrm{BH}_{4}\right)_{3}{ }^{+}$ & 5.6 & $19.3 \pm 1.3$ & $22.2 \pm 1.6$ & $1.1 \pm 0.2$ & - \\
\hline $\mathrm{Mg}_{2}\left(\mathrm{BH}_{4}\right)_{4}$ & 3.6 & $17.2 \pm 1.2$ & $18.9 \pm 1.9$ & $1.38 \pm 0.04$ & 3.8 \\
\hline $\mathrm{Mg}_{2}\left(\mathrm{BH}_{4}\right)_{5}^{-}$ & 1.9 & $4.4 \pm 1.0$ & $6.0 \pm 1.0$ & $2.64 \pm 0.12$ & - \\
\hline
\end{tabular}

${ }^{\mathrm{a}}$ Formula without THF molecules

${ }^{\mathrm{b}}$ Average number of coordinating THF molecules per cluster

${ }^{\mathrm{c}}$ Change in dielectric constant including loss of free THF

${ }^{\mathrm{d} C h a n g e}$ in dielectric constant ignoring loss of free THF

${ }^{\mathrm{e}}$ Characteristic reorientation frequency

${ }^{\mathrm{f}}$ Effective radius of gyration

Table S4. Computed Calcium Cluster Parameters from MD Simulations.

\begin{tabular}{|l|c|c|c|c|c|}
\hline \multicolumn{1}{|c|}{ Formula $^{\mathrm{a}}$} & THF Number $^{\mathrm{b}}$ & $\Delta \varepsilon_{\text {net }}{ }^{\mathrm{c}}$ & $\Delta \varepsilon_{\text {gross }}{ }^{\mathrm{d}}$ & $f(\mathrm{GHz})^{\mathrm{e}}$ & $R_{\mathrm{g}}\left(\AA^{f}\right)^{f}$ \\
\hline $\mathrm{Ca}\left(\mathrm{BH}_{4}\right)^{+}$ & 4.8 & $21 \pm 2$ & $24 \pm 3$ & $1.0 \pm 0.3$ & 3.5 \\
\hline $\mathrm{Ca}\left(\mathrm{BH}_{4}\right)_{2}$ & 3.8 & $-2.1 \pm 1.1$ & $1.9 \pm 1.2$ & $16 \pm 8$ & 3.7 \\
\hline $\mathrm{Ca}\left(\mathrm{BH}_{4}\right)_{3}^{-}$ & 1.9 & $-2.1 \pm 1.4$ & $0.4 \pm 1.7$ & $47 \pm 8$ & 2.5 \\
\hline $\mathrm{Ca}_{2}\left(\mathrm{BH}_{4}\right)_{3}{ }^{+}$ & 7 & $24 \pm 3$ & $24 \pm 4$ & $0.67 \pm 0.02$ & - \\
\hline $\mathrm{Ca}_{2}\left(\mathrm{BH}_{4}\right)_{4}$ & 5.6 & $16 \pm 2$ & $15.1 \pm 1.4$ & $1.07 \pm 0.03$ & 4.5 \\
\hline $\mathrm{Ca}_{2}\left(\mathrm{BH}_{4}\right)_{5}^{-}$ & 4 & $-2.1 \pm 1.1$ & $1.9 \pm 1.1$ & $23 \pm 7$ & - \\
\hline
\end{tabular}

${ }^{\mathrm{a}}$ Formula without THF molecules

${ }^{\mathrm{b}}$ Average number of coordinating THF molecules per cluster during MD simulation

${ }^{c}$ Change in dielectric constant including loss of free THF

${ }^{\mathrm{d}}$ Change in dielectric constant ignoring loss of free THF

${ }^{\text {e}}$ Characteristic cluster reorientation frequency

${ }^{\mathrm{f}}$ Effective radius of gyration 


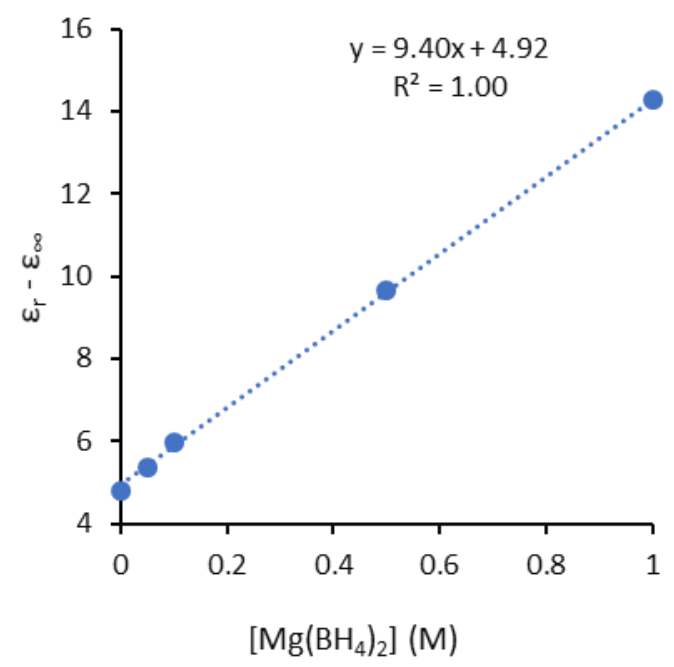

Figure S3. Measured dipole reorientation contribution to the dielectric constant of $\mathrm{Mg}\left(\mathrm{BH}_{4}\right)_{2} / \mathrm{THF}$ as a function of salt concentration. A linear fit trend line and its parameters are shown. A net $\Delta \varepsilon$ of $9.4 \mathrm{M}^{-1}$ is derived from this fit, similar to the predicted value of the neutral monomer $\left(8.9 \mathrm{M}^{-1}\right)$.

a)

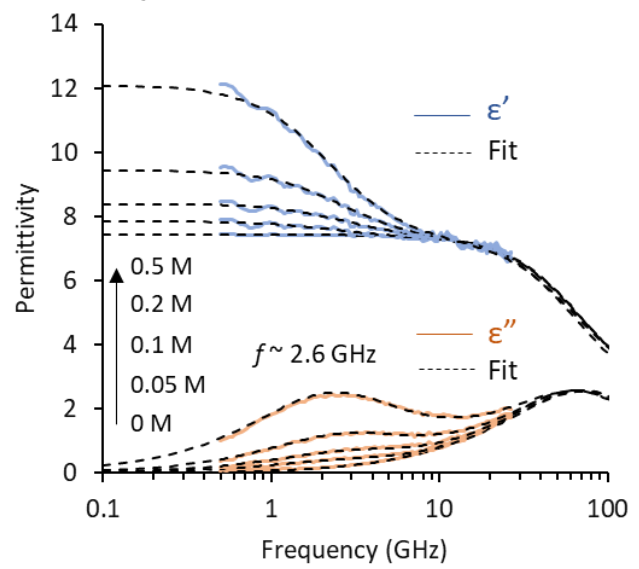

b)

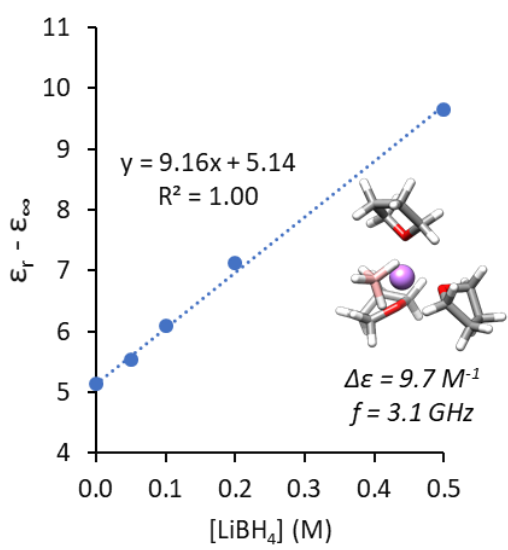

c)

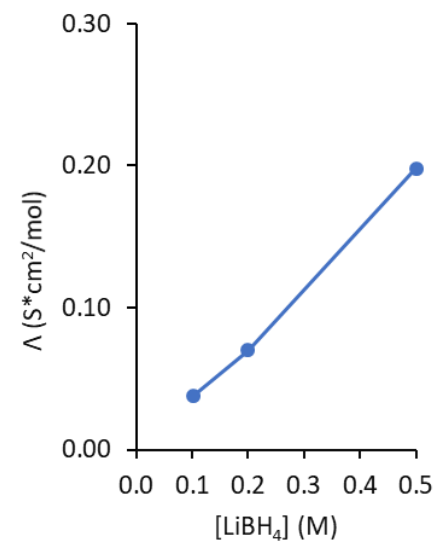

Figure S4. a) Dielectric spectra (real and imaginary components) measured for various $\mathrm{LiBH}_{4}$ concentrations in THF. Dashed lines represent fits of the data using two Debye relaxations. b) Dipolar contributions to the total permittivity extracted from DRS fits as a function of $\mathrm{LiBH}_{4}$ concentration. A linear fit to this data yields an effective $\Delta \varepsilon$ of $9.2 \mathrm{M}^{-1}$. The computed structure of the $\mathrm{LiBH}_{4} \mathrm{CIP}$ cluster, including its relevant dielectric relaxation parameters determined through MD simulations is overlaid. Both the computed $\Delta \varepsilon$ and relaxation frequency $(f)$ agree very well with the experimentally derived parameters. $\mathrm{Mg}$, $\mathrm{B}, \mathrm{C}, \mathrm{H}$ and $\mathrm{O}$ atoms are shown in purple, pink, grey, white and red, respectively. c) Molar conductivities measured for $\mathrm{LiBH}_{4}$ in THF. The values are small (similar to $\mathrm{Ca}\left(\mathrm{BH}_{4}\right)_{2}$ at these concentrations) indicating weak dissociation, consistent with a population dominated by neutral CIPs. 


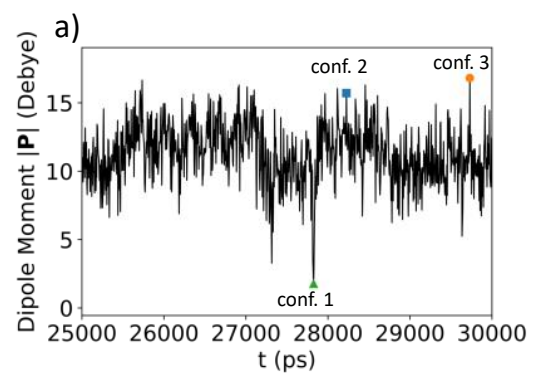

b)

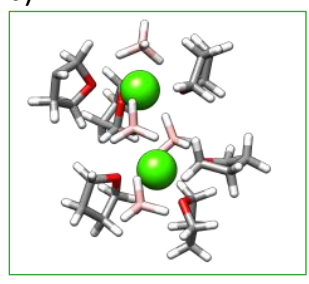

configuration 1 c)

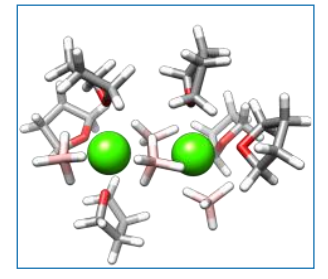

configuration 2 d)

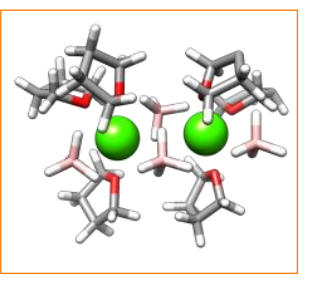

configuration 3

Figure S5. a) Dipole moment magnitude of the $\mathrm{Ca}_{2}\left(\mathrm{BH}_{4}\right)_{4}$ dimer in solution vs. time during the MD simulation trajectory in units of Debye. The dipole moment plotted here is of the ionic complex which includes contributions from the ions but excludes contributions from any solvent molecules. b) Example of linear (planar) geometry of the dimer species encountered during the MD simulation (c) Example of bent geometry of the dimer species encountered during the MD simulation. (d) Example of polar pyramidal geometry of the dimer species encountered during the MD simulation. $\mathrm{Ca}, \mathrm{B}, \mathrm{C}, \mathrm{H}$ and $\mathrm{O}$ atoms are shown in green, pink, grey, white and red respectively.

a)

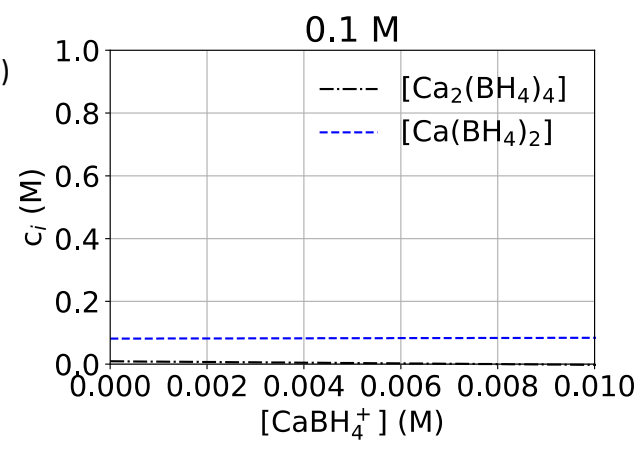

c)

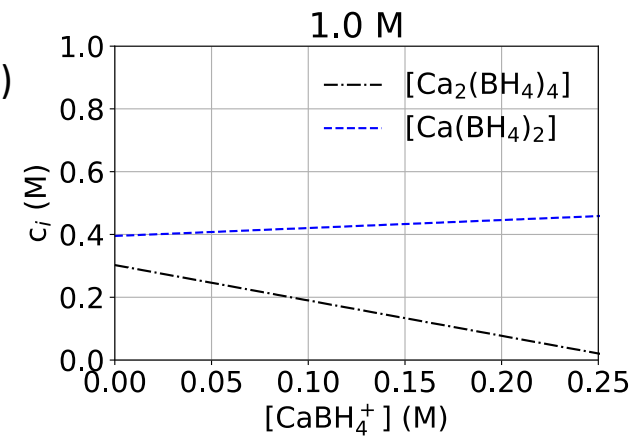

b)

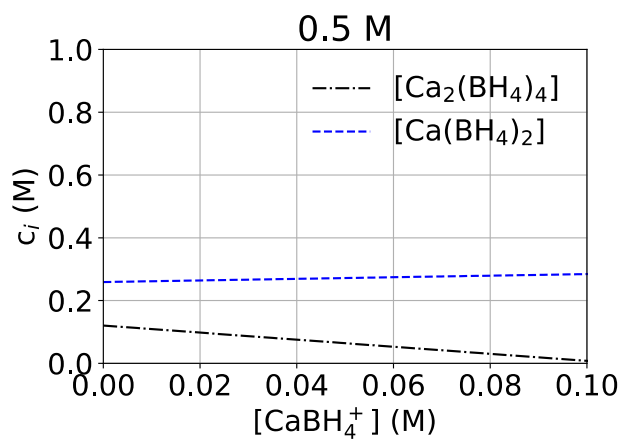

d)

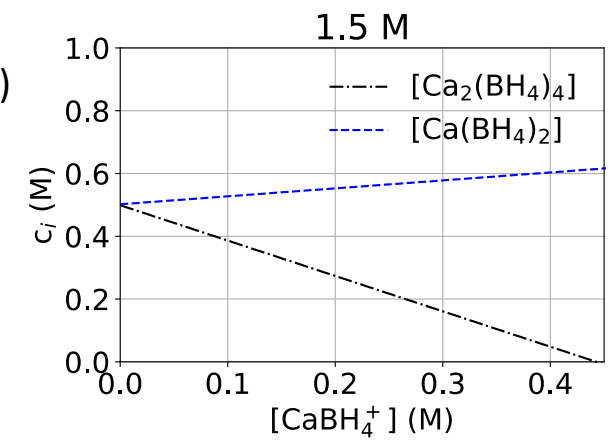

Figure S6. Calculations of the ranges of species concentrations that could satisfy the overall measured change in dielectric constant for $0.1 \mathrm{M}(\mathrm{a}), 0.5 \mathrm{M}$ (b), $1.0 \mathrm{M}(\mathrm{c})$, and $1.5 \mathrm{M}$ (d) $\mathrm{Ca}\left(\mathrm{BH}_{4}\right)_{2}$ in THF as a function of $\mathrm{CaBH}_{4}{ }^{+}$concentration. Fixing the value of $\left[\mathrm{CaBH}_{4}{ }^{+}\right]$based on the conductivity and diffusivity measurements provides more precise estimates of the actual populations, as shown in the main text (Fig. 4). 


\section{References}

1. Hahn, N. T.; Self, J.; Seguin, T. J.; Driscoll, D. M.; Rodriguez, M. A.; Balasubramanian, M.; Persson, K. A.; Zavadil, K. R., The critical role of configurational flexibility in facilitating reversible reactive metal deposition from borohydride solutions. Journal of Materials Chemistry A 2020, 8, 7235-7244.

2. Eberspaecher, P.; Wismeth, E.; Buchner, R.; Barthel, J., Ion association of alkaline and alkaline-earth metal perchlorates in acetonitrile. J Mol Liq 2006, 129 (1-2), 3-12. 